doi:10.17659/01.2017.0048

Journal of Case Reports 2017;7(2):174-176

\title{
Tetralogy of Fallot cases: Prone to be Affected by Malignancies or just a Coincidence?
}

\author{
Mohammad Radgoudarzi ${ }^{1}$, Seyyed-Mohsen Hosseininejad ${ }^{2}$, Mahdi Aarabi $^{3}$, Azizollah Yousefi $^{4}$, Alireza Ajam $^{2}$
}

Department of ${ }^{1}$ Pediatric Cardiology and ${ }^{4}$ Pediatrics, Hazrat-e Rasool General Hospital, Iran University of Medical Sciences, Tehran, Iran; ${ }^{2}$ Medical Student, Student Research Committee, Golestan University of Medical Sciences, Gorgan, Iran; ${ }^{3}$ Department of Orthopedic Surgery, Toronto East General Hospital, 825 Coxwell Avenue, Toronto, ON M4C 3E7, Canada.

\section{Corresponding Author:}

Dr. Seyyed-Mohsen Hosseininejad

Email: hosseininejad.s.mohsen@gmail.com

This is an Open Access article distributed under the terms of the Creative Commons Attribution License (creativecommons.org/ licenses/by/3.0).

Received

Accepted

Published

December 10, 2016

April 25, 2017

May 5, 2017

\begin{abstract}
Background: The tendency of developing malignancy in patients with congenital heart defects has been well documented. Osteosarcoma and tetralogy of Fallot (TOF) have never been so far reported to happen in a single patient. Case Report: An 8.5-year-old boy with history of repaired tetralogy of Fallot (TOF) one year back presented with refractory leg pain most frequently at nights. CT scan, bone scan and bone biopsy of the proximal part of the left fibula revealed: high grade intramedullary osteogenic sarcoma (OS) of osteochondroblastic type. Conclusion: According to latest genetic studies TOF and OS don't share any common genetic background; it would be interesting for clinicians to have in mind such tendency between TOF and OS to investigate if they share any origin genetically or developmentally?
\end{abstract}

Keywords: Bone Neoplasms, Heart Defects, Osteosarcoma, Pain, Tetralogy of Fallot.

\section{Introduction}

Primary osteosarcoma (OS) is the most common primary malignant tumor of bones, accounting for approximately $20 \%$ of primary bone cancers and predominantly affects patients younger than the age 20 [1]. Although it seems that the tendency of developing malignancy in patients with congenital heart defects has been well documented [2], association of osteosarcoma and tetralogy of Fallot (TOF) is rarely reported. We now present a rare association of surgically repaired TOF with osteosarcoma.

\section{Case Report}

An 8.5-year-old Fars boy with history of repaired TOF one year back was admitted to the Gorgan Taleghani Pediatric Hospital with complaint of refractory unilateral leg pain most frequently at nights. After corrective surgery of TOF one year back, he has been following with electrocardiography (ECG) and echocardiography [Fig.1]. He tolerated two major complications: right bundle branch block (RBBB) and severe pulmonary regurgitation (PI) without indications of pulmonary valve replacement. About 1 year later after surgery, the patient presented to our clinic for recently annoying left lower limb pain. While there was no known description associated with TOF itself or with complication of corrective surgery, initially the pain was attributed simply to the patient's flat soles. But the pain was nonresponsive, hence diagnostic approach accomplished step by step. Radiography showed mass in his proximal part of left fibula [Fig.2]. Computed tomography, bone scan and bone biopsy of the proximal part of the left fibula revealed: high grade intramedullary osteogenic sarcoma (OS) of osteochondroblastic type.

Chemotherapy with methotrexate, cisplatin, adriamycin was started. In the meantime, due to 


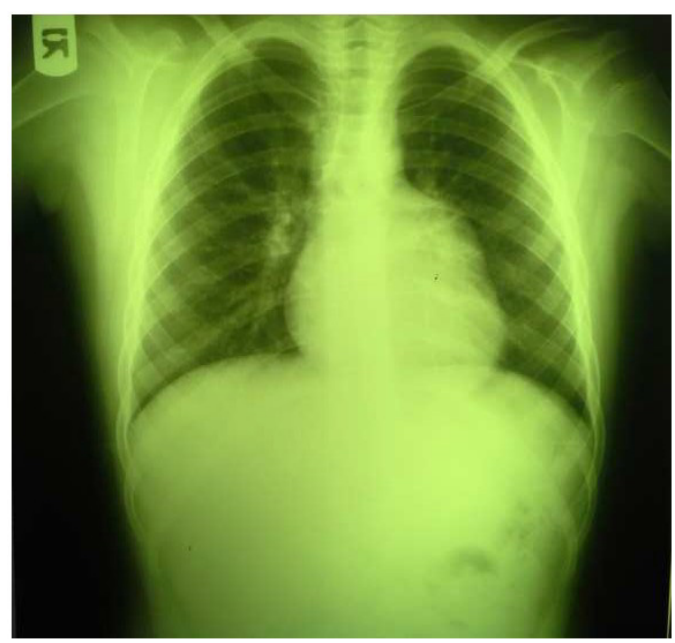

Fig.1: Chest X-ray of the patient indicating "Corrected TOF”.

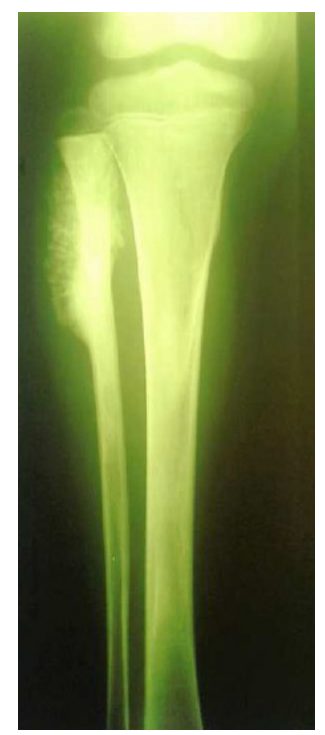

Fig.2: The lower limb radiography showing proximal fibular mass.

adriamycin he got bradycardia and actinomycin replaced adriamycin. After 3 months of chemotreatment, the patient was referred to surgeon for fibula resection [Fig.3]. The pre-operation metastasis survey including CT scans and PET scan was negative for any metastasis or regional organ involvement. The surgery was successfully carried out and postoperative chemotherapy started again with Pediatric Oncology Group (POG8651) protocol for OS.

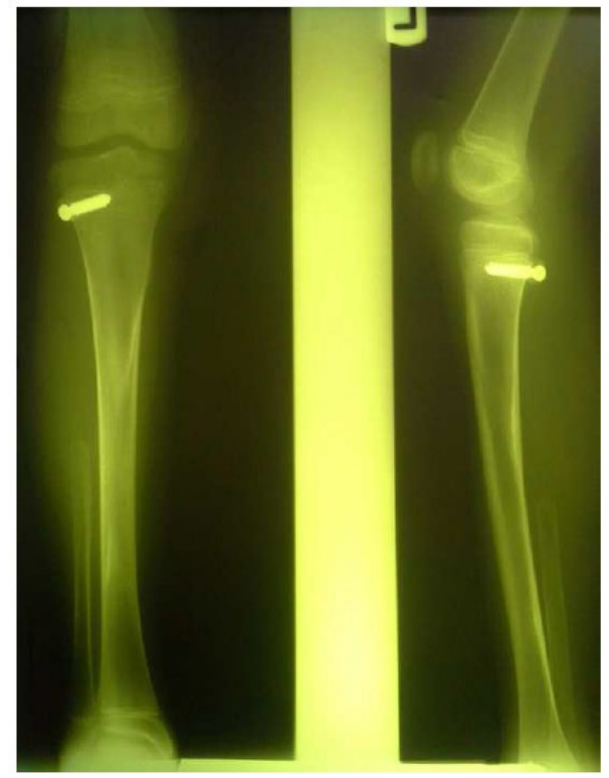

Fig.3: Post-surgical view of the left lower limb illustrating resected fibular mass.

After surgery, agenda was cardio-toxic chemotherapeutic agents which could exacerbate compensated right ventricular function inspite of free pulmonary valve regurgitation (free PI) and RBBB. After modulating chemotherapy plan and selecting the least cardio-toxic drugs, actinomycin replaced adriamycin here in our case with cardiologic consultation. Chemotherapy was continued with closed clinical observation. The patient has been followed up with echocardiography and electrocardiography (ECG) at regular intervals and before each session of chemotherapy. His chemotherapy was completed 13 month ago. No significant cardiac complications or recurrence of OS have occurred during recent year-follow up.

\section{Discussion}

CHD patients have significantly increased cancer risk, particularly hematologic, CNS, and head and neck malignancies [5]. Tetralogy of Fallot (TOF) is the most common form of cyanotic congenital heart disease, is often associated with other congenital cardiac or non-cardiac defects. Occurrence of TOF and some tumors (like right ventricular myxoma and adrenocortical tumor) in the same patient are 
increasingly reported recently [6,7]. However, its association of TOF with osteosarcoma is rarely reported. There is no report about co-occurrence of TOF and osteosarcoma until now in our current case.

TOF itself has some weird accompanies as schizophrenia [8]. Its surgical correction has some longstanding complications as RBBB and PI $[6,7]$, as happened in our case too. Nevertheless occurrence of TOF and some tumors (like right ventricular myxoma and adrenocortical tumor) in the same patient are increasingly reported recently Association of tetralogy of Fallot with invasive adrenocortical tumor has been reported previously and lately with congenital granular cell tumor.

OS, common in young patients, tends to occur at the sites of bone growth, most often in metaphysis of long bones [9] as in current case. Many patients initially complain of pain that may be worsened at nights as in current case. Other less frequent sign and symptoms include localized swelling and sudden fractures [10]. There is a known relation between TOF and some gene defects like 22q11 [11]. Familial cases of OS with deletion of chromosome 13q11 have been reported [12]. According to latest genetic studies TOF and OS don't share any common genetic background.

Management of patients with tetralogy of Fallot associated with osteosarcoma differs from that of patients with tetralogy of Fallot alone, whose management in most cases assures good long-term results. No reports have addressed prognosis of TOF in patients with osteosarcoma. Predictors of prognosis are yet to be determined in these patients.

\section{Conclusion}

This case shows that osteosarcoma may be associated with TOF. It would be interesting for clinicians to have in mind such tendency between TOF and OS to investigate if they share any origin genetically or developmentally?
Contributors: MR: study conception, case management and critical revision of manuscript; $\mathrm{SMH}, \mathrm{MA}, \mathrm{AA}$ : literature search and manuscript writing; AY: patient management and critical revision of manuscript. MR will act as guarantor. All authors approved the final version of the paper.

Funding: None; Competing interests: None stated.

\section{References}

1. Damron TA, Ward WG, Stewart A. Osteosarcoma, chondrosarcoma, and Ewing's sarcoma: National Cancer Data Base Report. Clin Orthop Relat Res. 2007;459:4047.

2. Holzer R, Franklin R. Congenital Heart Disease and Neuroblastoma: Just Coincidence? Arch Dis Child. 2002;87:61-64.

3. HT Lynch, GS Green. Wilms' Tumor and Congenital Heart Disease: Report of a Case and Family. Am J Dis Child. 1968;115:723-727.

4. Olsen M, Garne E, Sværke C, Søndergaard L, Nissen $\mathrm{H}$, Andersen $\mathrm{H \varnothing ,} \mathrm{et} \mathrm{al.} \mathrm{Cancer} \mathrm{risk} \mathrm{among} \mathrm{patients} \mathrm{with}$ congenital heart defects: a nationwide follow-up study. Cardiol Young. 2014;24:40-46.

5. Lee YS, Chen YT, Jeng MJ, Tsao PC, Yen HJ, Lee PC, et al. The risk of cancer in patients with congenital heart disease: a nationwide population-based cohort study in Taiwan. PLoS One. 2015;10:e0116844.

6. Mitropoulos F, Giannakoulas G, Kallifatidis A, Kanakis M, Kiaffas M, Chatzis A. Right ventricular myxoma in a patient with tetralogy of Fallot. Int J Surg Case Rep. 2014;5:1058-1060.

7. Tapia-Orihuela RK, Huaringa-Marcelo J, Loja-Oropeza D. Tetralogy of Fallot and pheochromocytoma in a situs inversus totalis: An unusual association. J Cardiovasc Thorac Res. 2016;8:132-136.

8. Piran S, Bassett A, Grewal J, Swaby J, Morel C, Oechslin E, et al. Patterns of cardiac and extracardiac anomalies in adults with tetralogy of Fallot. Am Heart J. 2011;161:131-137.

9. Harvey EL Teo, Wilfred CG Peh. Primary bone tumors of adulthood. Cancer Imaging. 2004;4:74-83.

10. Widhe B, Widhe T. Initial symptoms and clinical features in osteosarcoma and Ewing sarcoma. J Bone Joint Surg Am. 2000; 82:667-674.

11. Momma K, Takao A, Matsuoka R, Imai Y, Muto A, Osawa $\mathrm{M}$, et al. Tetralogy of Fallot associated with chromosome 22q11.2 deletion in adolescents and young adults. Genet Med. 2001;3:56-60.

12. Kuijjer ML, Rydbeck H, Kresse SH, Buddingh EP, Lid $\mathrm{AB}$, Roelofs $\mathrm{H}$, et al. Identification of osteosarcoma driver genes by integrative analysis of copy number and gene expression data. Genes Chromosom Cancer. 2012;51:696-706.

13. Oster M, Dawson A, Wetmore C, Grosse S. Association of congenital heart defects with childhood cancer in privately insured US children: A rapid claims analysis. Circulation. 2016;134:A15137. 